\title{
Revista de Estudios Sociales
}

\section{Changing Fortunes: Biodiversity And Peasant Livelihood In The Peruvian Andes}

Zimmerer, K. S. (1999). Changing Fortunes: Biodiversity and Peasant Livelihood in the Peruvian Andes.Berkeley and Los Angeles: University of California Press.

\section{Fabio Alejandro Camargo}

\section{Q OpenEdition}

\section{Journals}

Edición electrónica

URL: https://journals.openedition.org/revestudsoc/19056

ISSN: $1900-5180$

Editor

Universidad de los Andes

Edición impresa

Fecha de publicación: 1 abril 2008

ISSN: 0123-885X

\section{Referencia electrónica}

Fabio Alejandro Camargo, «Changing Fortunes: Biodiversity And Peasant Livelihood In The Peruvian Andes», Revista de Estudios Sociales [En línea], 29 | Abril 2008, Publicado el 09 agosto 2018, consultado el 04 mayo 2021. URL: http://journals.openedition.org/revestudsoc/19056

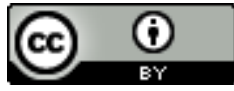

Los contenidos de la Revista de Estudios Sociales están editados bajo la licencia Creative Commons Attribution 4.0 International. 


\section{Changing Fortunes:}

\section{Biodiversity and Peasant Livelihood in the Peruvian Andes}

Zimmerer, K. S. (1999). Changing Fortunes: Biodiversity and Peasant Livelihood in the Peruvian Andes. Berkeley and Los Angeles: University of California Press.

\section{Fabio Alejandro Camargo*}




\section{E} ste texto estudia la función sociocultural y ambiental de la diversidad de los cultivos agrícolas en los Andes de Paucartambo, Perú. Se enfoca principalmente en los cultivos de maíz, papa, ulluco y quinua localizados a lo largo de un paisaje agrícola formado por espacios de cultivos como la loma y el valle, en los cuales trabajan campesinos indígenas de la sociedad quechua. Tal diversidad es analizada por el autor a la luz de diversos procesos que han llevado a su deterioro, lo cual se convierte en una preocupación contemporánea por la pérdida de la biodiversidad, en contraste con la búsqueda de mecanismos de conservación que conlleven un desarrollo "económicamente sano y socialmente justo”.

A lo largo del libro, Zimmerer muestra que la diversidad de los cultivos no sólo se da por las características ambientales de un lugar sino también por la acción de las personas que los trabajan. Éste es, precisamente, uno de los puntos fuertes del texto, pues problematiza el concepto de biodiversidad alejándose de la posición que la entiende como una condición per se, "natural", producto de las condiciones de un ambiente aparentemente inalterado por los seres humanos, y en contraste, muestra que, en el caso de los Andes de Paucartambo, la biodiversidad se ha visto influenciada por procesos históricos y políticos que han determinado su destino. Procesos históricos, en tanto los diferentes momentos de la historia de la región, en particular durante el Imperio inca, la colonización española y el gobierno republicano, han influido a su modo en las transformaciones de la agricultura y la explotación de unos cultivos en detrimento de otros. Políticos, en tanto muestra, por ejemplo, cómo después de la Reforma de Tierras llevada a cabo por el Estado peruano en 1969 se produjo un cambio radical en la relación de los campesinos con la tierra mediante el cultivo de diferentes alimentos, pues además de poner en marcha nuevas formas de manejo y uso de la tierra, arraigó en la región una lógica de producción agraria orientada al cubrimiento de la demanda de mercados extrarregionales y urbanos.

La Reforma de 1969 es un momento crucial en el análisis de Zimmerer, pues desde ese entonces la diversidad de los cultivos sufrió serias alteraciones, que se dieron en un contexto de transformaciones ecológicas, ambientales y socioculturales. Desde el punto de vista ambiental, la especialización en la producción de cultivos de variedades mejoradas de mayor resistencia y menor tiempo de maduración, la adopción de técnicas y herramientas agrícolas para el rendimiento de los cultivos - tales como fertilizantes y fungicidas- y la intensificación de la ganadería conllevaron al deterioro y la erosión de los suelos y el detrimento de la diversidad de los cultivos, a favor de la intensificación de la producción de unos pocos de gran importancia comercial.

De igual forma, la Reforma ocasionó profundos cambios en la organización sociocultural de los campesinos quechuas. Con su vinculación a la economía agrícola comercial, se formó una gama de sectores socioeconómicamente diferenciables, en cuyo polo se ubicó una gran parte de campesinos pobres con pocos recursos y oportunidades de acceso al mercado, y del lado opuesto, cultivadores con mayor poder adquisitivo y, por lo tanto, con los medios técnicos y las tierras para hacer parte del comercio agrícola, con la particularidad de que tal acceso no implicó el detrimento de los cultivos de diversas variedades. En un lugar intermedio se encontró un grupo de campesinos que poseen tierras y medios para acceder al mercado pero no son lo suficientemente solventes como para mantener de la misma forma cultivos variados en sus territorios.

Dado que los campesinos más acomodados lograron mantener una producción para el comercio sin "sacrificar" la diversidad de cultivos de uso tradicional, gracias, entre otras cosas, a la vinculación de mano de obra externa a su familia, Zimmerer resalta cómo se produce un cambio cultural en el significado de los cultivos diversificados. Durante la Colonia, la diversificación agrícola se veía como una característica de la vida de los indígenas, de donde los españoles acuñaron el término peyorativo de "comida de los indios", pero tras la Reforma de Tierras de 1969, esta diversidad se resignifica, pues para los campesinos más adinerados se convierte en una especie de "lujo tradicional" que da cierto estatus social.

La diversidad en los cultivos no es sólo producto de las condiciones ambientales sino también de las prácticas culturales de los campesinos, quienes no siempre están motivados por razones ecológicas, sino también por la búsqueda de una supervivencia plena, o kawsay, en palabras de los indígenas, lo cual determina unas normas culinarias que incentivan la siembra de diversos cultivos para la elaboración de diferentes platos. Sumado a ello, además de que los cultivos cumplen un rol alimenticio, también tienen diferentes papeles dentro de la sociedad quechua, tales como ser elementos rituales en las fiestas religiosas, servir de objeto de intercambios recíprocos y de regalos que fortalecen los diferentes lazos de parentesco real o ficticio, 
y de amistad entre los campesinos. Incluso, hacen parte de los argumentos para reclamar los derechos de subsistencia ligados al uso de la tierra, en algunos momentos de tensión frente al Estado y sus políticas.

De esta forma, a pesar del cambio cultural y de la inserción de la economía de mercado y la comercialización de productos agrícolas que intensificaron la "erosión genética", la diversidad de cultivos se logró mantener entre algunos sectores del campesinado de Paucartambo. Esto contradice aquellos postulados que sostienen que con la "aculturación" de las sociedades tradicionales, generalmente asociada a su vinculación con las dinámicas del mercado capitalista, inevitablemente hay una pérdida de biodiversidad. El cambio cultural en sociedades indígenas no implica la extinción del cultivo de diversos productos, afirma Zimmerer. En contraste, los campesinos de los Andes de Paucartambo, mediante la innovación, lograron mantener una producción agrícola con doble propósito: el comercio y la subsistencia, que significó ajustes tecnológicos, laborales y de manejo de los recursos, tal y como se puede ver en la creciente flexibilidad de los sistemas productivos y en la creación de espacios de siembra, donde mezclan diversas variedades de cultivos.

Changing Fortunes no sólo es una contribución a los estudios sobre el campesinado y los recursos naturales agrícolas en Perú, sino también una crítica a las visiones adaptacionistas, con la intención de problematizar el concepto de biodiversidad, tan en boga a partir del crecimiento de los movimientos ambientalistas y de las alarmas sobre el deterioro de nuestros recursos naturales. De igual forma, es un aporte significativo a los estudios sobre la alimentación, pues expone cómo en torno al propósito de obtener una subsistencia plena a través del cultivo de diversas variedades -para aumentar las posibilidades culinarias heterogéneas y de comercialización de alimentos- se da una serie de transformaciones culturales y ambientales que conllevan a la formación de nuevas relaciones de poder y de resignificación de la función social y ambiental de los cultivos y su diversidad.e 